\title{
Research progress in man-land relationship evolution and its resource-environment base in China
}

\author{
LI Xiaoyun ${ }^{1,2},{ }^{*}$ YANG Yu ${ }^{1,2}$, LIU Yi ${ }^{1,2}$ \\ 1. Institute of Geographic Sciences and Natural Resources Research, CAS, Beijing 100101, China; \\ 2. University of Chinese Academy of Sciences, Beijing 100049, China
}

\begin{abstract}
Man-land relationship research, as the core of geographical research, runs through each development stage of Geography. Based on extensive literature review, this paper systematically generalizes the connotations, research development and contents of man-land relationship in China. (1) It explores the connotations and evolvement rules of man-land relationship in different social development stages in China, and finds that the core role of man-land relationship in geographical research has been strengthened continuously. Changing with times, its connotations have been considerably enriched by sustainable development and other notions, and so does its theoretical system. (2) It applies the bibliometric method to sketch out the basic research status of man-land relationship in China. Specifically, it quantitatively identifies the funding sources, major research teams and journals for publication. It finds that the funding sources show a diversification trend with national funding being the primary source of research grants. The most competitive research teams are mainly concentrated in the Institute of Geographic Sciences and Natural Resources Research, Chinese Academy of Sciences (CAS) and normal universities. Journals sponsored by The Geographical Society of China are most influential in publishing man-land relationship research. (3) As resources and environment are the fundamental carriers of man-land relationship, this study focuses further on the research on resource-environmental base of man-land relationship, and finds that the resource-environmental base research in China has gone through an evolution process from single factor perspective research to comprehensive multiple perspective research gradually. Research themes have also experienced similar changes from land, water, energy minerals or other single factor research to comprehensive factor research of resources and environment. Empirical study on national and regional development strategies is the feature of man-land relationship in China. More emphasis should be put on considering and following the changes in features of "man" and "land" and research on the impacts of new factors on man-land relationship in a developing and dynamic manner in the future. Particularly, we should pay more attention to research on the impacts of spatio-temporal changes in resource-environment absolute location on modes of man-land interaction, and to strengthening interdisciplinary research and systematic research on comprehensive techniques so as to advance the development of application of man-land rela-
\end{abstract}

Received: 2016-08-12 Accepted: 2016-09-30

Foundation: National Natural Science Foundation of China, No.41430636, No.41371141, No.41590841

Author: Li Xiaoyun (1989-), PhD, specialized in man-land relationship and regional development. E-mail: lixy.15b@igsnrr.ac.cn

*Corresponding author: Yang Yu (1984-), Associate Professor, specialized in energy geography and regional development. E-mail: yangyu@igsnrr.ac.cn 
tionship theories and practices.

Keywords: China; man-land relationship; resource; environment; progress

\section{Introduction}

Since the beginning of modern industrial civilization, rapid technological advances have resulted in huge conflict between human and the earth along with tremendous wealth accumulation. Meanwhile, the limited resource-environment basis and its security have been facing more and more pressures caused by double-quick growth in human beings' consumption demand and structural changes, especially for developing countries with a huge population and strong desire for development (Zhang et al., 2002). A country can recover from the trauma of war but it can never still develop in the damaged natural environment (Gaylord, the founder of Earth Day). Once the stability of resource and environmental basis has been damaged, the normal order of society will inevitably be shaken and even disrupted (Zhang, 2008). From the modern geography sprung up in the late 19th century to contemporary geography after the Second World War, the basic theoretical research has always been centered on the relationship between human being and geographical environment. A series of schools such as the Environment School, Region School, Landscape School and so on which have exerted immense influence on contemporary geography have emerged according to their different perspectives of exploring geographical environmental changes, distribution rules, and its internal relationship with human activities. Even to this day, the crux of a range of increasingly severe global issues like scramble for strategic resources, incontrollable regional environmental pollution, food security guarantee, climate warming, urban sprawl, poverty, and sustainable development, etc. is still the problem of relationship between human activities and resource environment. In the development report of Geography by the National Research Council of the National Academies, US - Understanding the Changing Planet: Strategic Directions for the Geographical Sciences, it states explicitly that close attention must be paid to the relationship between human being and resources...the emerging and existing evolution characteristics of earth biophysics and human environment must be attached great importance to. Man-land relationship research has been and will always be the core proposition of geographical research throughout every development stage of geography, which is drawing more and more attention from Sociology, Ecology, Environmental Sciences, Complexity Science, and other cross-disciplinary fields. In fact, Chinese and western man-land relationship research has different emphases in subjects and perspectives against disparate cultural and social backgrounds. In English speaking countries, "Human-environment interaction" is the term for "Human/man land relationship" which is most commonly used by Chinese scholars. In recent years, the research perspectives of western countries have begun to shift from human activities and geographical environmental changes to more specific aspects such as city safety, urban environmental changes, poverty and environmental issues, sustainable development of resources and so on. Leading research teams are no longer made up of human-economic geographers either, but are dominated by Environmental Sciences, Ecological Sciences, and Complexity Science instead. Resources, ecology, environment and managing measures of them have become a bridge connecting "human" and "nature" research. Resource and environment research is taking on an obvious 
trend of being more and more human and social. The key concepts in Geography, namely "space" and "territory", have also gradually become important carriers for the combination of "human" and "environment" research. These are all well reflected in Chinese man-land relationship research as well, but compared with western researches, ours focus more on macro-perspective empirical studies, and have played a significant role in national and regional development strategies like Major Function-oriented Zone Planning, Construction of Ecological Civilization, and Strategic Environmental Assessment, etc. The feature of "emphasizing practices and diminishing theories", however, has led to the relatively slow development of the theoretical system of China's man-land relationship research to some extent at the same time.

The rise of empirical studies has been driven by the discipline development orientation of "being led by missions". To serve national and regional development strategies is the characteristic of Chinese man-land relationship research and of Chinese economic geography research as well. As the largest developing country in the world, whether China can establish a solid foundation of resources and environment is a major practical and unavoidable issue in its national sustainable development. Since the reform and opening up, China's progress in social and economic development has drawn the attention of the world. Since 2010, China has become the world's second-largest economy. However, the rapid economic growth is accompanied by enormous cost of resources and environment, which will exert continuous pressure and severe challenges on China's further development (Liu et al., 2014). Judging from the total amount of resources, China can be regarded as one of the resource-rich countries in the world, but due to its large population, the per capita share of many kinds of resources such as water, soil, minerals, forests, etc., are less than the world average. The amount of China's comprehensive resources is only $58 \%$ of the world average, ranking 53rd in the world (Zhang et al., 2014). More worrying still is that the exploitation and utilization efficiency of resources has been keeping at a very low level in China. The comprehensive utilization rate of minerals is only about $35 \%$ which is 20 percentage points lower than the international advanced level. This has resulted in huge gap between the demand and supply of some important mineral resources and a strong external dependence. The imports volumes of many resources, including oil, iron ore, copper, and aluminum and so on, rank the first among all the countries. In 2010, China became the world's largest consumer of energy and the world's largest carbon emitter as well. China's energy self-sufficiency rate has shown a downward trend year by year because of the strong consumption demand for energy. Moreover, due to the insufficiency of energy supply, the shortage of four important kinds of energy, i.e. coal, gas, oil and electricity has been normalized in China. Furthermore, environmental pollution is becoming more and more serious; large areas are continually shrouded in severe fog and haze; soil is contaminated by heavy metal; solid waste is increasing; water quality is deteriorating; desertification area is expanding, plus the appearance of cancer villages and extreme weather conditions and so on, all of which are real reflections of a disharmonious relationship between human and the earth and an uncontrolled internal process of man-land system.

As a catching-up industrialized country, China has to strive for economic growth at a moderately fast speed in a long period of time so as to conduct long-term industrialization construction on the basis of a large population and a relatively low level of social productive 
forces. Some studies have shown that the national resource-environment safety coefficient of China is much lower than the world's average level. In the meantime, the national economic development continues to consume massive resources, and the continuing trend of environment deterioration cannot be reversed in a short term. As a result, China will continue to be faced with the dual pressures of promoting economic development and protecting resources and environment ( $\mathrm{Lu}$ et al., 2009; Zhang et al., 1999). Environmental protection has penetrated into various fields of international politics and economy and has been set as a new tariff barrier which brings about new restrictions on China's export of products. Fulfill a number of international environmental treaties and agreements at one time also pose a great challenge to China. Faced with so many realistic problems, we have to re-examine the question "who will feed the Chinese?" Whether and to what extent the existing resources and environment base can support our socio-economic development in the future? As the active subject in the man-land relationship, what else can we human beings do to achieve the prospect of sustainable development, and what should we do?

These questions, directly or indirectly guiding the direction of Chinese man-land relationship research, have become value orientation of man-land relationship research. This paper, focusing on these questions, discusses the theoretical and empirical explorations of Chinese scholars from a geographical perspective. By means of scientific literature computation analysis tools, it collects and analyses relevant literatures and systematically elaborates the evolution process of China's man-land relationship research. As input factors of human activities, resources and environment are the carriers of human activities and the carriers of numerous negative ecological environment effects caused by the human activities as well. In the face of an increasingly intense man-land relationship, it's very necessary to reexamine the resource-environment base including land, water, energy and mineral resources as well as ecological environment resources, etc. on which China's economy and society can develop sustainably. For this purpose, this paper will conduct a further review of existing studies on resource-environment base to grasp the framework, topics and future direction of man-land relationship research in China more deeply.

\section{Data and method}

The data used in this paper mainly comes from the core journals database of China National Knowledge Infrastructure (CNKI) which is the world's largest continuously and dynamically updated academic journal full text database. It is also the most widely used and influential Chinese database (www.CNKI.net) for bibliometric analysis. The scientific computation and visualization software CiteSpace will be used for statistical analysis. CiteSpace (free download site http://cluster.cis.drexel.edu/ cchen/citespace/) is a bibliometric analysis tool developed by the Chinese-American scholar Dr. Chen Chaomei. It can display the development trend of a subject in a certain period by analyzing the keywords co-occurrence in relevant studies (Liu et al., 2014). By means of classifying literatures and limiting journal sources, the paper collects relevant core journal studies of man-land relationship in Geography and related disciplines.

Due to the wide range of man-land relationship research coverage, broadly speaking, all geographical studies can fall into the research scope of man-land relationship. Although certain articles do not necessarily mention the terms like "man-land relationship", their research 
content is actually part of certain aspect of it. In this respect, relevant achievements cannot be more fruitful. If we set macro-terms such as "man-land relationship", "resources (water, land, energy, minerals, sea, grassland, etc.)", and "environment" and so on as search query, more than 10,000 articles will be listed. After further analysis of the listed literatures, we find, however, it is true that the broad search covers a wide range of researches, but many of the articles have similar or even duplicate research subjects or contents, which will bring great difficulties to a systematic and targeted review of man-land relationship literatures. In a narrow sense, man-land relationship, as a theoretical system, should have its own independent theoretical development course and connotations. There should be easily identifiable core theories and empirical system of it, even though it has a wide coverage. Furthermore, as the research core of a subject, "man-land relationship" has already had plenty of studies directly related to it. Paying attention to those directly related studies can not only help discover the evolution of the connotations of geographical research core, it is also beneficial for the understanding of extended research directions. Therefore, for the sake of more concentrated research subjects, this study mainly starts from the narrow-sense perspective and focuses on the researches directly related to "man-land relationship" so as to identify its evolution process as a theoretical system and relative research development. To be specific, firstly, it selects the relevant fields of studies in CNKI, including Geography, Resources Science, Environmental Science and Resource Utilization, etc. Secondly, among all the journals of geography and key journals of resources and ecology, it limits the journal sources as core journals about geography, resources and environment by compiling professional searching code. And then, "man-land relationship" is employed as the search query for relevant literatures. Finally, it eliminates duplications and completely irrelevant items such as the Call for Papers for journals, etc. We have got a total of 689 Chinese papers (by January 7th, 2016) as a result. For a more accurate result, we compared and analyzed the articles listed under different searching patterns and found that these papers were always listed in all searching patterns. This shows that these papers have key position in man-land relationship research and are highly influential, basically covering all the major contents of man-land relationship research. For this reason, this paper mainly conducts bibliometric analysis on these literatures, and discussion is developed based on review of these literatures.

\section{Evolutions of man-land relationship connotation and research}

\subsection{Evolution of man-land relationship connotation}

Man-land relationship refers to the interaction and feedback between human and nature on the earth surface, which has always been regarded as the core issue of geographical research (Lu et al., 1998). Man-land relationship came into being along with human society. Human beings began to perceive their surroundings through simple production activities long ago and thereby accumulated early geographical knowledge. Gradually, they began to explore the relationship between human activities and geographical environment (Wu, 1991). Generally speaking, man-land relationship includes human beings' dependence on nature and their active role as well (Zheng, 2002). In various historical periods, however, due to the differences in human abilities to understand, utilize and reconstruct the nature, the connotation of man-land relationship has been changing in both scope and depth with the develop- 
ment of social productive forces.

The history of man-land relationship development formed in the process of human-nature interaction is also the history of human social development (Guo et al., 2001). According to the degree of human's dependence on nature, the evolution process of man-land relationship connotation can be roughly divided into four stages. The first stage is primitive civilization period in which the level of productive forces was low and human beings had to passively adapt to and excessively depend on the nature. "The theory of nature and destiny" (natural disasters, good or bad years in agricultural production and even the rise and fall of nations are all decided by the Heaven) was the typical perception of man-land relationship during this period of time. The subsequent "mechanical materialism" (human beings and the earth are closely linked, but the development rules of the earth dominate everything) also contains the implication of human beings' worship to the Earth. The second stage is agricultural civilization period in which productive forces had been fairly improved, and human beings began to utilize labor tools and gradually master some irrigation and farming techniques. As human's ability to reconstruct nature was being improved, new views on man-land relationship emerged correspondingly, among which the "simple dialectical materialism" (geographical conditions are variable and can be different for different people) became the core concept dealing with man-land relationship during that period of time. The relationship between man and land at that time could be generalized as simple and low-level coordination. The third stage is industrial civilization period with rapidly strengthened social productive force. Under the guidance of the notion that "man can conquer nature by his efforts", human beings' active role was greatly strengthened. The connotation of man-land relationship in this period mainly manifested as human's conquest and domination over nature. Along with the long-term and high-intensity exploitation and transformation of the nature by human society, man-land relationship is becoming increasingly strained. Resources and environmental crises break out constantly which even threaten the survival of mankind themselves. The conflict between human and nature urges us to re-examine our activities and conception, and make us gradually aware that only human society develops harmoniously with the nature can we achieve the goal of sustainability. The fourth stage began in the 1980s. The idea of sustainable development has enriched the connotation of man-land relationship. Human beings, with a higher level of social productivity, expect to seek coordination between human and nature again. Comparing the development stage of China with the evolution process of man-land relationship connotation, we can find that currently the man-land relationship in China is in the third or the transitional period from the third to the fourth stage.

\subsection{Evolution of man-land relationship research in China}

Thoughts of man-land relationship have very deep cultural roots in China. According to the traditional Chinese cultural view of "unity of man and nature", ancient Chinese geography emphasized the unification and interaction between human and land. Many ancient classics, like The Classic of Mountains and Seas, Book of Han, Treatise on Geography etc., contain the thought of adjusting actions according to the circumstances which integrate all the factors of timing, geographical and human conditions into account. However, the ancient geographical research on man-land relationship in China was mostly descriptive and lists of phenomena, lacking systematic and cause-and-effect analysis. Until the beginning of the 
20th century, marked by the founding of The Geographical Society of China, modern Chinese geography began to develop, and man-land relationship research entered scientific advancement (Wang et al., 2001). Nevertheless, the development of Chinese modern geography is deeply influenced by western thoughts, including the "Geographical Environment Determinism", "Probabilism", "Theory of adjustment", "Human ecology", "Cultural landscape theory" etc., especially the "Dualism" in Soviet Union's geography which separates natural elements from economic factors. Under the great influence of this thought, Chinese geography once neglected the research on the issue of man-land relationship. Until the early 1990s, Academician Wu Chuanjun put forward the idea that "man-land areal system is the core of geographical study" (Wu et al., 1991), and thought that systematology viewpoints should be applied to study the interaction between the two categories (groups) of elements on the earth surface - elements of human system and land system. Wu's insight highly condensed the connotation of coordinating the relationship between human and nature by which the development of modern geography has been instilled new vitality (Wang, 1995).

After drawing out the temporal graph of keywords evolution from 1980 based on the analysis of literature keywords by using the Citespace software and clustering of bursting points (Figure 1), we found a number of keywords outburst during the evolution process of man-land relationship research, including "geographical study", "Wu Chuanjun", "man-land system", "man-land relationship areal system", "sustainable development", "regional development" and "urbanization", etc. These keywords reveal focuses of attention of the academic circles on man-land relationship in different periods of time. From Figure 1, we can see that the connotation of man-land relationship has changed significantly since the 1980s.

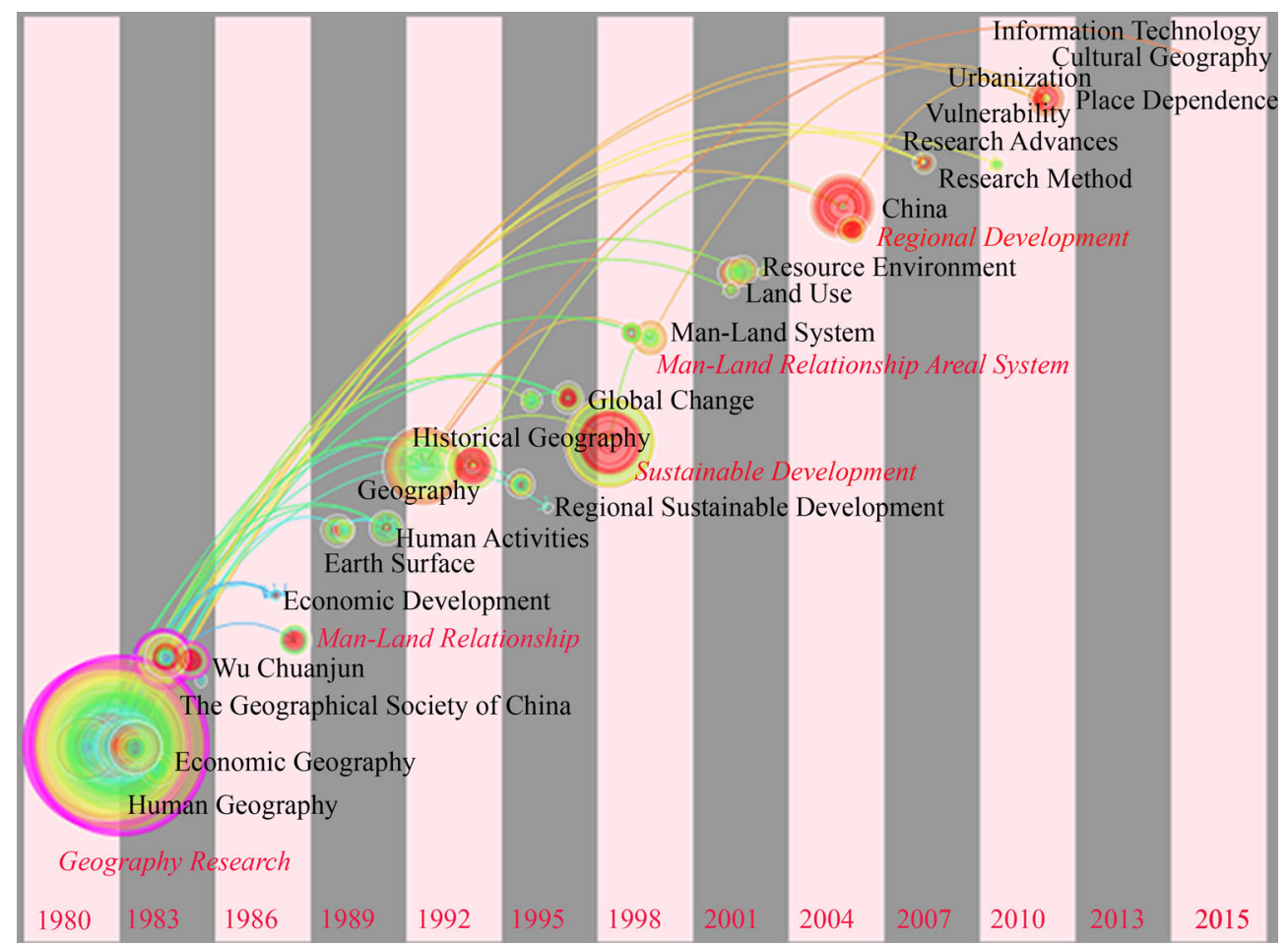

Figure 1 The temporal graph of man-land relationship research keywords co-occurrence in Chinese core journals 
In the 1980s, the most concerned keywords are "earth surface", "economic development", "man-land system", etc., and man-land system began to become the core topic of geography study, especially of human geography and economic geography study. In the 1990s, "regional sustainable development", "human activities", "global change", etc. became the hottest issues in human geography. Since the eary 21 st century, the widely concerned issues have evolved into "resources and environment", "land utilization", "vulnerability", "urbanization", "information technology", "place dependence" and so on. This graph of keywords evolution presents the basic thread of modern Chinese man-land relationship research.

Most of all, since the mid-1990s, sustainable development has attracted the attention of geographers and been highly concerned for many years afterwards. The core of man-land relationship research gradually turned into discussion about coordinated development patterns of regional PRED (population, resources, environment and development) system (Mao, 1995; Ye, 2001; Wang, 1997; Cai, 1998). Later on, some scholars further developed the traditional PRED system into PREEES (population, resources, environment, ecology, economy, society) system (Fang, 2004) and PESRE (population, economy, society, resources, environment) system (Zhao et al., 2004). But no matter which system it is, how to accurately grasp and quantitatively express the interactive mechanism between the various elements inside the system have always been the hot and difficult problems for man-land relationship research. Exploration into related research methods also became a hotspot at a time. The studies on man-land relationship in this period focus more on the integration of multi-disciplinary knowledge, and the methods employed tend to be more diversified. Different methods and new techniques are applied to break the research bottleneck. For example, the 3S technology (GIS, GPS, RS) has been used to obtain a great quantity of spatio-temporal data and achieve the visualization of the data. System integration method is also introduced to strengthen the integrated study on the influence and intervention of human activities on "man-land relationship areal system" (Lu, 2002) through modeling and parameter study. Typical models include system dynamics model, the nonlinear dynamic model and so on. The comprehensive index system evaluation method, which evaluates the sustainable development ability of regional man-land system comprehensively by establishing relevant evaluation index system (Wen et al., 1999; Jia et al., 2003), has led modern human geography research into a new chapter.

Taking a certain region as the unit for comprehensive study of man-land relationship is the unique characteristic of Geography ( $\mathrm{Wu}, 1991)$. Thus among all the existing papers, those studying the man-land relationship of specific regions by using a combination of modern technologies such as the geographic information system, remote sensing technology and so on with the methods of index system, mathematical models, etc. make up the majority. Especially for typical regions with a relatively more sensitive man-land relationship, such as ecologically vulnerable areas, rapid urbanization areas, mountainous areas, etc., the studies tend to involve the contents like the evolution, structure and optimization of regional man-land relationship (Wang, 1995; Zhang, 2000; Sun et al., 2000; Chen, 2000; Zhang et al., 2004). From the viewpoint of study scale, most of the researches are conducted at a macro or medium-scale, and only very few of them concerning micro-scale (Qiao, 2015). In recent years, some scholars have even rethought the essence of man-land relationship areal system from a philosophical perspective. They think traditional Chinese culture should be intro- 
duced to develop and enrich the research on man-land relationship (Ye, 2001; Zhou, 2015; Sun, 2012), and even further put forward the "trialism" of man-land relationship study (Lv et al., 2013), i.e. introducing "cultural factors" between the "human system" and "land system", for they believe that culture is the fundamental driving force for the evolution of man-land system. Generally speaking, man-land relationship research has been enriched by different scholars from various perspectives.

Throughout the evolution process of man-land relationship research in China, in general, under the guidance of the subject tenet - making study serve practical purposes, Chinese geography has timely adjusted its research perspectives to the demands of development with the same unshakable research core of man-land relationship though. This has differentiated Geography from other disciplines and laid a solid theoretical foundation for its man-land relationship research. Nevertheless, as mentioned earlier, compared with international research, ours have the common features of emphasizing macro research and practices but diminishing micro research and theories. Since Academician Wu Chuanjun put forward the man-land relationship system theory, relative theories have always been improved, but theoretical innovation has been inadequate. Besides, in China, the degree of division is greater than that of integration between the sub-disciplines of Geography. Future studies need to broaden their horizon and employ more perspectives, pay more attention to internationally significant propositions, especially the "Future Earth" programme and other frontier researches in the world, combine them with the man-land relationship research with a Chinese characteristic, and explore theoretical innovation that is more in line with Chinese man-land relationship. The core concept and basic framework of the "Future Earth" programme are highly consistent with the widely accepted man-land relationship areal system theory in Chinese geographical circle. It has extended the impacts of man-land interaction on human society to fields such as "livelihood, health, wealth, value, security, social justice, human welfare" and so on. The depth and width of its research perspective are yet to be attained by Chinese man-land relationship researches. All of these are worthy of profound consideration by follow-up studies.

\subsection{The overall characteristics of man-land relationship research}

\subsubsection{Number and journal distribution of papers}

Generally speaking, the number of papers on man-land relationship published in Chinese core journals of geographical science has had a growing trend year by year since 1980 (Figure 2a). This reveals that geographers have been paying more and more attention to man-land relationship, which also shows that the core position of man-land relationship in geographical research has been strengthened continuously. Especially since 1992, with global change being the hot issue of the day, the perspectives of man-land relationship research have been enriched gradually, resulting in an increasing number of papers published in relevant areas such as sustainable development, coordinated regional development, man-land relationship areal system, land use, resources and environment, etc. Related papers mainly published in more than 20 journals, including "Acta Geographica Sinica", "Scientia Geographica Sinica", "Geographical Research" and so on (Figure 2b). By analyzing the total citations of papers published in these journals, we find that "Acta Geographica Sinica" is the most frequently cited journal with a total cited frequency of up to 2000 times, followed by 
"Human Geography", "Economic Geography" and "Scientia Geographica Sinica" successively, all of which have been cited more than 1500 times. These journals, all sponsored by the Geographical Society of China, have significant impact on man-land relationship study and are the major academic territories for Chinese geographers to publish their research achievements.
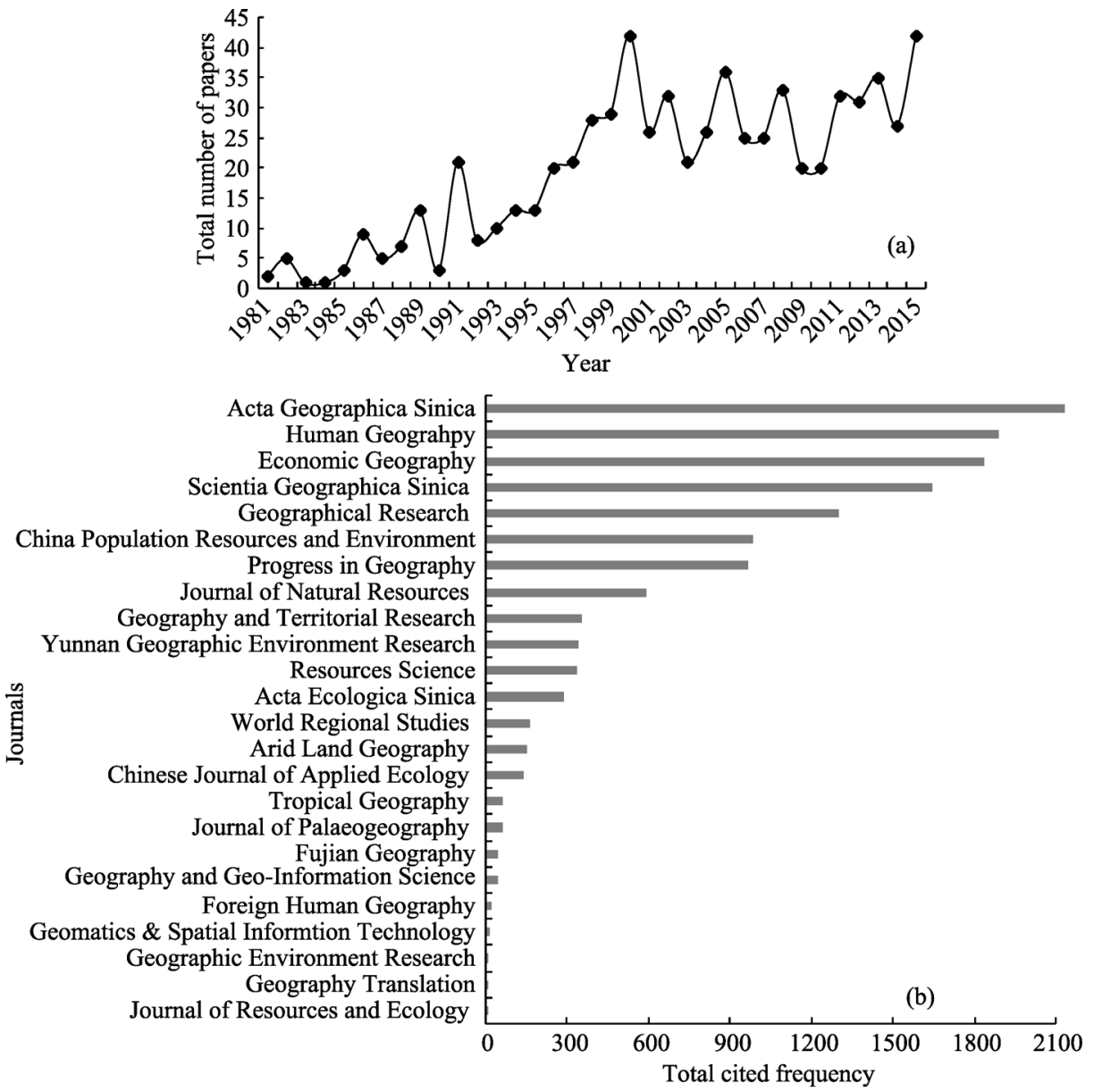

Figure 2 Number of published papers of man-land relationship in geographic core journals per year (a); distribution and citations of journals of man-land relationship related papers since 1980 (b)

\subsubsection{Sources of funds}

A statistical analysis has been done on the funding sources of relevant literatures showing a diversification trend of the research grants which can be largely divided into five categories: national funding, provincial/municipal funding, funding of Chinese Academy of Sciences (CAS), higher education funds and other funds (Figure 3). Judged by the number of papers supported by different funds, national funding is the major source of research grants, the proportion of papers supported by which in all the funded papers has reached to $74.6 \%$. The national funding includes National Natural Science Foundation, National Social Science Foundation, National 973 Program, National Science and Technology Support Program, etc., among which the National Natural Science Foundation is the most important in supporting 
man-land relationship study. Up to $55 \%$ of all the related papers are funded by it. The proportions of papers funded by the provincial/municipal funds, CAS funds and Ministry of Education funds are $8.4 \%, 8.1 \%$ and $6.2 \%$ respectively. Although these funds only make up a small proportion compared with the national fund, they also play a crucial role in promoting regional man-land relationship research. In particular, CAS Knowledge Innovation Program, One Hundred Person Project, Major Projects of resources and eco-environmental research, and research projects deployed by the Institute of Geographic Sciences and Natural Resources Research have made significant contributions to the advancement of the basic theoretical and empirical study on man-land relationship. That is also the main reason why CAS is always on the frontier of man-land relationship research.

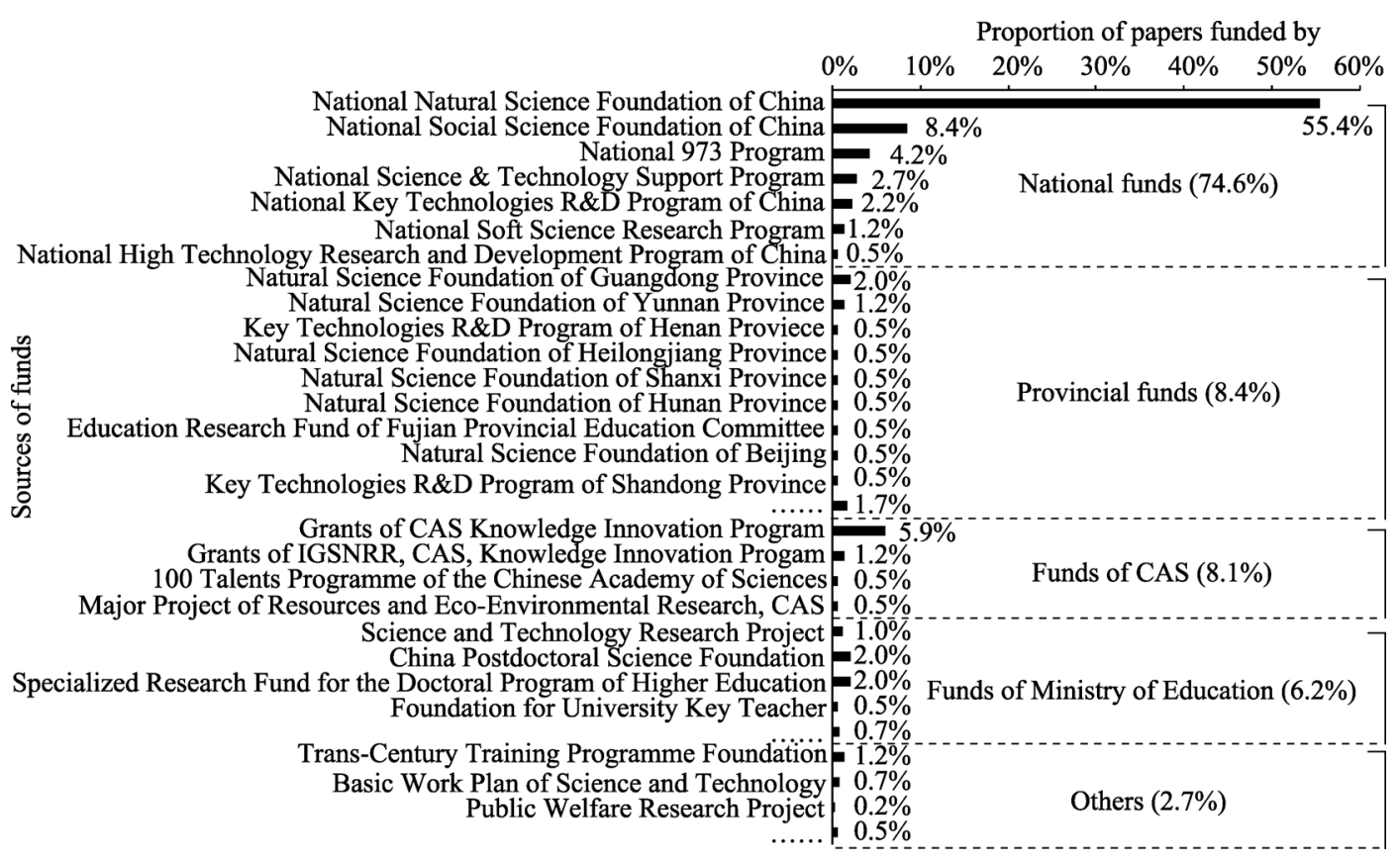

Figure 3 Fund sources of man-land relationship related studies

\subsubsection{Research institutions}

According to the statistical results, the Institute of Geographic Sciences and Natural Resources Research, CAS who has published a large number of research achievements on man-land relationship is the top-level institution in this field. It is far ahead of other institutions or universities in both the total number of articles published and total cited frequency (Figure 4), accounting for half of the studies on man-land relationship. In addition, another 40 institutes and universities including Peking University, Sun Yat-sen University, Henan University, Northeast Normal University, Nanjing University and Beijing Normal University have also paid long-term attention to man-land relationship research and have gained remarkable achievements in this field. Apart from famous traditional universities of Geography, such as Peking University, Sun Yat-sen University, Henan University, Nanjing University and so on, normal universities and colleges are the main undertakers of man-land relationship research having a strong influence in this field. 


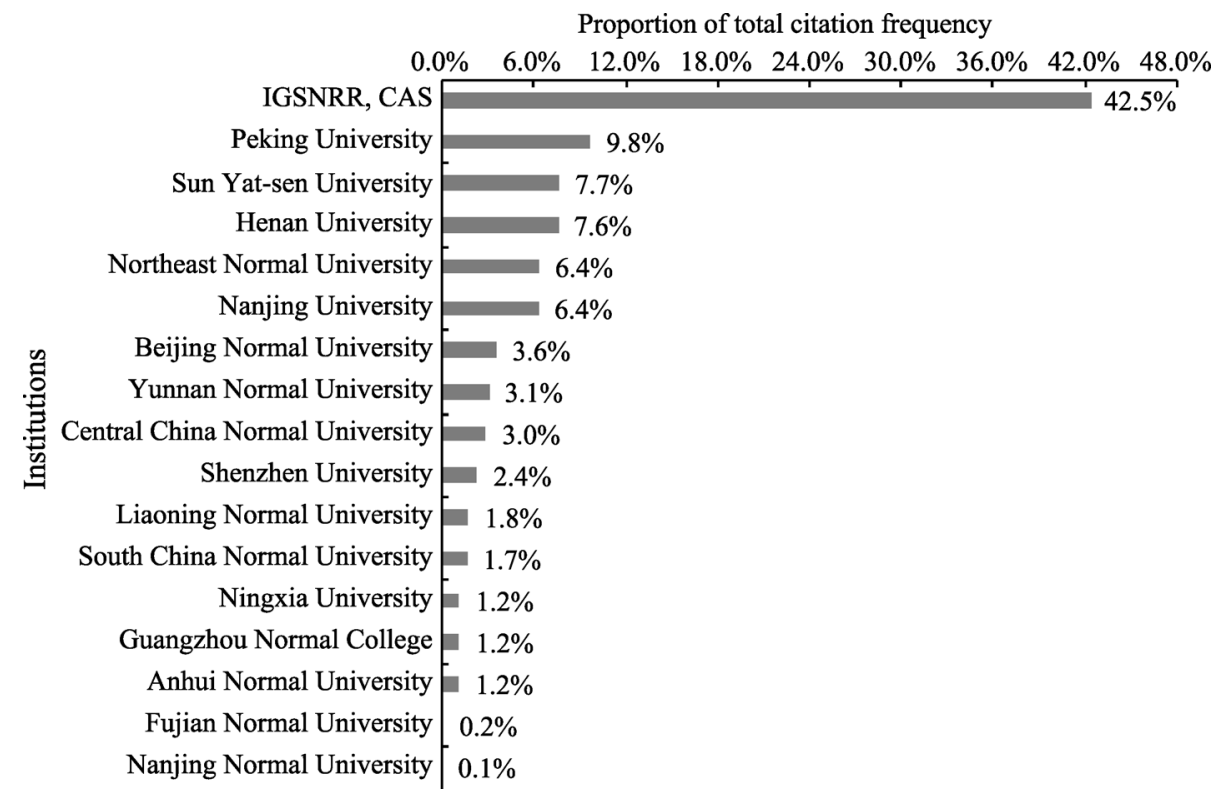

Figure 4 Distribution and total cited frequency of research institutions in related fields of man-land relationship research

Note: IGSNRR, CAS is the abbreviation of Institute of Geographic Sciences and Natural Resources Research, Chinese Academy of Sciences.

\subsubsection{Research teams}

By identifying the authors and research teams of man-land relationship studies, we find that there are nearly 40 major research teams, led by renowned scholars such as Wu Chuanjun, Lu Dadao, Zheng Du, Liu Weidong, Zhang Lei et al., in the field of man-land relationship study in China. Their various research achievements are constantly enriching the theoretical study of man-land relationship and its practical application from different perspectives. For example, the academic team led by Academician Lu Dadao mainly focuses on the "human elements" in man-land relationship, like economy, industry, traffic, etc., and most of their researches are concerned about medium- and long-term national development strategy from a macro perspective. The total cited frequency of articles published by this team ranks first and their research achievements have exerted significant influence on man-land relationship study in the geographical circle. The team led by Academician Zheng Du focuses principally on the "land elements" in man-land relationship, like water, climate, etc. and studies the patterns and evolution rules of these elements. Their studies have laid a solid foundation for the further research of man-land relationship. The team led by Professor Fan Jie concerns resources-environment carrying capacity and the organization and transformation of regional spatial patterns. From the perspectives of resource carrying capacity and major regional functions, their teams put forward the basic theory of managing and regulating modern man-land relationship. Professor Zhang Lei and other scholars mainly study the resourcesenvironment foundation and protection of man-land relationship. Generally, all the scholars have their own research focuses and strengths, and made their own contributions to the man-land relationship study. All of their research achievements have enriched the research field, which the paper will not give details one by one here (Figure 5). 


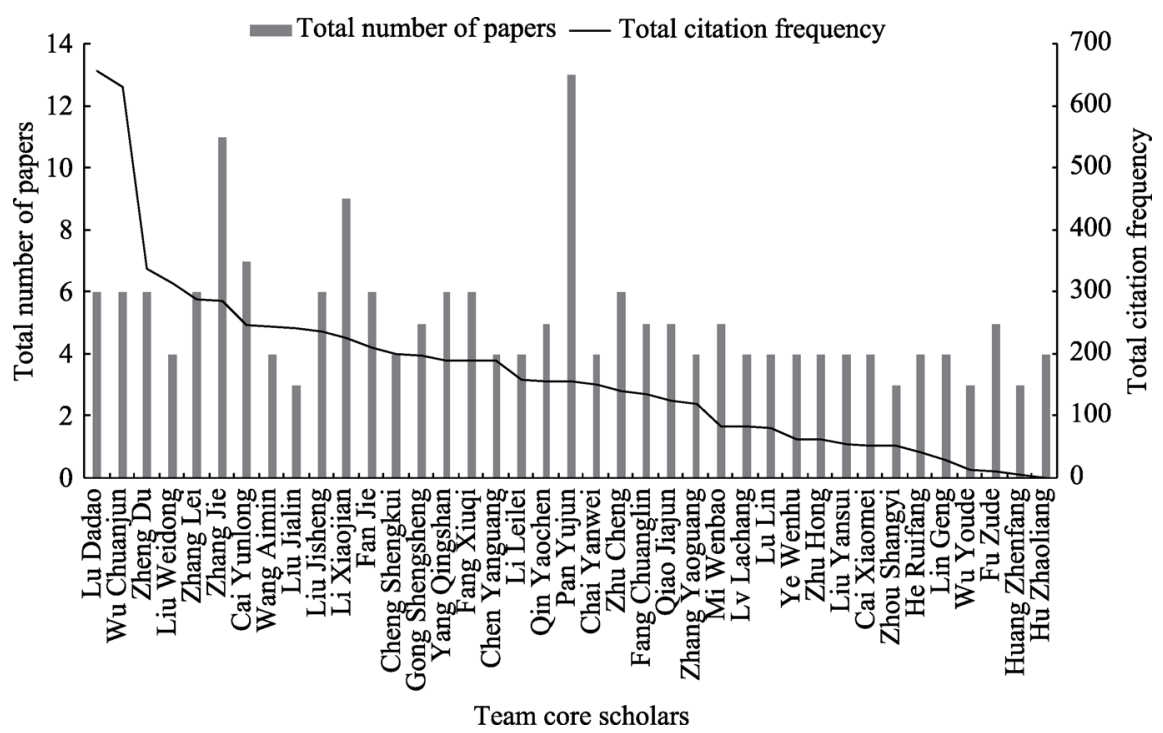

Figure 5 Number of papers published by man-land relationship research teams and their citation frequencies

\section{Resources and environmental base of man-land relationship in China and research progress}

As the basis for the birth and development of mankind and their civilization, resources and environment always play a core role whether in man-land relationship areal system or in PRED system. The evolution of man-land relationship also reflects that the degree of human beings' exploitation and utilization of surrounding natural resources is gradually deepening. It is proved by long-term practices that the spatial patterns of human activities are determined by the structure and conditions of regional resources and environment in China. Even to this day, the spatial pattern of Chinese population distribution still has not broken the boundaries defined by comprehensive natural elements. The "Hu Line" (1935) that displays the spatial difference of population distribution has been relatively stable over the 80 years (Qi et al., 2015), showing that the foundation of Chinese man-land relationship is very solid. And the objective basis of forming and maintaining this line lies in the spatial composition characteristics of resources and environment from the national macro level (Liu et al., 2010). It is particularly important for China, a large developing country with a huge population, to understand these foundational functions of resources and environment in order to develop sustainably. Therefore, the research on resources and environmental foundation is a non-neglected major issue in man-land relationship research.

\subsection{Comprehensive research of resources and environmental base}

"Resources and environmental base" is a compound concept, and the comprehensive research on it embodies the subject characteristics of geographical research. From the core point of man-land relationship, the resources and environmental base mainly refers to all the material sources on which human society relies on for survival and development. At different historical stages, the inputs of resources and environmental factors required by the de- 
velopment of human society are quite different. In ancient times, the input of resources and environmental factors was of obvious singularity. Whereas in modern times, it shows prominent wholeness. Accordingly, the research of resources and environmental base in China has undergone an evolution process from a single-factor perspective to a comprehensive multi-factor perspective. Meanwhile, research topics have also gradually evolved from single-factor research on land resource, water resource, energy or mineral resource, etc. to integrated research of resources and environmental factors. Major function oriented zoning, raised in recent years, is the practical application of the comprehensive evaluation of resources and environmental base.

As the scientific foundation for putting forward Major Function Oriented Zoning (Fan, 2007), resources and environmental carrying capacity is the epitomizing of comprehensive research of resources and environmental base, and an important criterion for evaluating regional man-land relationship (Wang et al., 2007). Be it the earlier single-factor research on resource carrying capacity which centered on "cultivated land-food-population", "water resources-population", or the later multi-factor research concerning "resources - environment population", carrying capacity, as an important method to weigh the interest relationship among all factors so as to meet the demands of both human beings and environment, has always been regarded as one of the important criteria for the evaluation of coordinated regional man-land relationship as well as one of the core methods to quantitatively assess the capacity of sustainable development (Graymore et al., 2010). More and more attention has been paid to resources and environmental carrying capacity, and relevant research perspectives fall into three categories. The first one is to evaluate single-element with multi-functional comprehensive carrying capacity based on the synthesized carrying functions, like the comprehensive research on the multi-functional carrying capacity of land resources, i.e. natural, social, ecological, economic functions, etc. The second one is to study multi-elements carrying capacity based on element synthesis. The third one is compound carrying capacity research based on the integration of multi-elements and multi-functions. Theoretical study mainly involves the characteristics, influencing factors, early warning and development evaluation of regional resources and environmental carrying capacity (Zhou et al., 2015; Wang et al., 2013; Xiong et al., 2012). Empirical research largely includes a series of significant national or regional sustainable development strategy research, such as major function oriented zoning and post-disaster (earthquake and other serious natural catastrophes) restoration and reconstruction study (Fan et al., 2014; Gao et al., 2010; Ding, 2009). From the perspective of case study areas, existing research not only involves macro-scale regions, like the western region and urban agglomeration areas, but also concerns meso-scale regions, e.g. Yunnan, Zhejiang and other provinces and micro-scale districts and counties. Major research methods include comprehensive index evaluation method, model coupling method, system dynamics method, state-space method and ecological footprint method, etc., among which to establish index system is the core step for evaluating the carrying capacity of resources and environment. Scholars have constructed various index systems according to their different research purposes (Lei et al., 2016; Qin et al., 2011). However, further improvement of the index system and exploration of the integrated quantitative method are still the principal research directions of the comprehensive evaluation of regional resources and environmental carrying capacity and resource-environment base. 


\subsection{Single factor research of resources and environmental base}

\subsubsection{Land resource research}

Land resource is of special importance to human survival and development (Shi, 2006). From a geographical perspective, land is at the most fundamental position in the "population-resources-environment-development (PRED)" compound system (Liu, 2002). Also, the above mentioned bibliometric analysis shows that no matter how the core topics change during the evolution process of man-land relationship research, land has always been one of the hot topics concerned by the academic community. Especially since the 1990s, the demand for sustainable development being stronger than ever before, the world has paid high attention to the study of land resources, and even more so in China where land resources are relatively scarce under the background of rapid urbanization. The characteristics of China's land resource can be summarized as follows: the average per capita is low; land types are complex and diverse; the spatial distribution of it is uneven, and regionally speaking, productivity differences are obvious; even worse, the problems of land desertification and soil erosion are serious. The purpose of land resource study is to make better use of land and to coordinate the increasingly strained relationship between human and land (Long, 2003). China has launched two large-scale national land resources survey in 1984-1996 and 2004-2009 respectively, through which we have got complete and specific information about the situation of land resource in China, including land use type, quantity, quality and distribution rules, and generated a series of maps, database and research reports based on the information, which has laid a solid foundation for subsequent land resource management and academic research in China.

At present, the subjects of land resource research from the perspective of man-land relationship can be divided into four major categories: The first is land use / cover change (LUCC) and its driving mechanism. Land use / cover change (LUCC) reflects the most direct and closest interaction relationship between human and nature (Cai, 2001), which has become an international front subject in the comprehensive study of geography (Chen et al., 2003). From the identification of land use / cover conditions (Gao et al., 1999) to the revelation of the spatio-temporal patterns of land use / cover change (Liu et al., 2003), and then to the analysis of the driving mechanism of land use/ cover change (Wang et al., 2002) and the eco-environmental effects (Li et al., 2002; Fu et al., 2005), the research on land use / cover change is gradually deepening. In particular, the comprehensive studies about land use / cover change in typical regions provide scientific evidence for coordinating the relationship between regional land resource and human activities (Zhang et al., 1999; Wang et al., 2004). The second is land consolidation and optimal allocation. Land consolidation, as an important means to coordinate man-land relationship, to realize the optimal allocation of land resource and to improve the land use intensity degree, plays a major role in relieving conflicts between human beings and land and solving land use problems (Luo et al., 2001). Since the 1980s, under the special background of China, there appeared a large number of hollow villages and the phenomenon of land abandonment, which caused a serious waste of land resource (Chen et al., 2010), village habitat environment deterioration and slowness of economic development in the rural areas (Li et al., 2008). Therefore, the climax in the study of 
land consolidation appeared, which has gradually been developed into major measures for stimulating domestic demand, promoting new-countryside construction, and balancing urban and rural development. The research involves aspects like land consolidation / land optimal allocation models (Ni et al., 1999), benefit analysis (economic benefit, social benefit, ecological benefit and comprehensive benefits) (Zhang et al., 2003; Hu et al., 2004), eco-environmental effects of land consolidation (Luo, 2002), land restoration in ecologically fragile areas (Huang et al., 2003), etc. All the achievements yielded from the above researches have provided scientific references for reasonable and effective utilization of land resource. The third is land evaluation. Land evaluation which provides basic reference standards for coordinating man-land contradictions is the core field of land resource research. It mainly includes land suitability evaluation (Zong et al., 2007), land use intensity degree evaluation (Guo et al., 2006; Wang et al., 2004), land safety / bearing capacity evaluation (Leng et al., 1999), ecological environment effects and ecological safety evaluation of land resource (Liu et al., 2004), land sustainable development/utilization potential evaluation (Peng et al., 2001; Liu et al., 2001), etc. The fourth is carrying capacity of land resource. Since the late 1980 s, the research of land carrying capacity has developed rapidly. It mainly includes calculating the production potential of land resource based on the measurement of biological production quantity (e.g. grain and pasture value) or intensity of human activities (e.g. construction intensity) (Xu et al., 2015);or evaluating the relative carrying capacity of regional land resource by comparing it with reference regions and set-threshold values (Yue et al., 2008); some scholars also study comprehensive land carrying capacity from multiple perspectives of nature, economy, society and eco-environment, etc., (Wang et al., 2001). Currently, the research of land carrying capacity is gradually moving from static analysis to dynamic prediction, from qualitative analysis to quantitative simulation. Major methods include series model method, index system method, agro-ecological zone method, questionnaire investigation method, etc., among which series model method is most popular, including land use dynamic degree model, spatial partition model, structure optimization model, digital environment model, the pressure-state-response model, etc. In recent years, remote sensing, GIS and other modern scientific and technological means have also been widely applied to the research of land resource in China.

\subsubsection{Water resource research}

Water resource is a fundamental natural resource and strategic economic resource which has been listed as one of the three strategic resources together with food and oil resources in China (Xia et al., 2013). The water resources in China have notable features of low per capita, uneven spatio-temporal distribution, unmatched structure of water and soil resources, and susceptible to human activities. Additionally, the rapid socio-economic development has resulted in prominent contradiction between the supply and demand of water resource. We are faced with multiple problems which can be generalized as "much water (floods), little water (droughts), muddy water (soil erosion), and dirty water (water pollution)", etc.

Water resource relevant research has been a very active and dynamic research field since the 1990s and has become an important subject area supporting the sustainable development of China. There have successively appeared a large number of research achievements. Generally speaking, related researches mainly focus on four aspects. Firstly, it is the study on 
evolution rules of water resource, including water cycling mechanism and the effects of water resource on human activities and eco-environment (Ouyang et al., 2004; Li et al., 2012), the hydrological response to climate change and the impacts of human-nature double factors on water resources (Xia et al., 2011). Secondly, it is the study on water resource utilization. Centered on water resource sustainable utilization, based on the evaluation of the status quo of water resource exploitation, studies on evaluation index system of sustainable utilization of water resource, prediction of ecological reservoir, analysis of the exploitation threshold of regional water resource development (Lai et al., 2006; Gao et al., 1997; Liu et al., 2003; Yan et al., 2001) have been conducted. In addition, great achievements have also been made on the research of the development and utilization efficiency of water resource as well as closely related issues like water-saving agriculture and engineering techniques (Tan et al., 2016; Kang et al., 2004; Zhao et al., 1996). Thirdly, it is the study on water resource management and protection. Water resource management research mainly discusses issues like water rights, water price (Pei et al., 2003), and water resource allocation etc., which includes the approaches, models and methods of reasonable and optimal allocation of water resource for sustainable and efficient utilization of water resource (Feng et al., 2003; Wu et al., 2016). As water-related problems increase, research subjects concerning the safety and protection of water resource, like water quality, water pollution, ecological environment of water resource, water safety and countermeasures as well as the evaluation of it, have also been widely concerned by scholars (Li et al., 2000; Xia et al., 2002a; Jia et al., 2004; Jiang, 2001; Jia et al., 2002). Fourthly, it is the study on water resource carrying capacity. It is the further deepening of water resource safety and protection issues and one of the core researches for finding out the development potential of national resources and environment. In recent years, relevant research achievements have emerged one after another, most of which focus on the concept, connotation, evaluation index system, quantitative model and method, etc. (Liu et al., 2011; Duan et al., 2010; Hui et al., 2001; Long et al., 2004; Zhu et al., 2003). As for the distribution of case study areas, existing researches mainly concentrate on basin-scale and macro-scale like northwest arid area or meso-scale such as the Yangtze River Basin, Yellow River Basin and Heihe River Basin. Besides, Xinjiang Uygur Autonomous Region is also one of the research hotspots. Popular research methods include: conventional trend method, system dynamics method, multi-objective comprehensive analysis method, water footprint method, analytic hierarchy process, model construction method, index measurement method, etc.

\subsubsection{Energy and mineral resource research}

Energy and mineral are the principal driving force for social production, and the major source of raw materials of many chemical products (Zhang, 1999). The evolution of energy utilization has gone through three stages: the firewood era, coal era, and the oil and gas era. No matter in which of the eras, energy is always an indispensable factor for the development of economy (Chen, 2009). However, as the mankind is consuming more and more energy, especially fossil fuels, its constraint on socio-economic development and negative impact on the environment becomes increasingly prominent (Jing, 2008). At the present stage, the basic characteristics of energy and mineral resources in China can be summarized as: numerous in variety but low in per capita share; production growth is rapid but utilization efficiency is low; consumption demand is large while eco-environmental pressure prominent; an 
energy structure dominated by coal consumption needs to be optimized.

The studies related to energy resources have always been concentrated on energy structure and pattern, energy security and strategy, energy efficiency and economic growth, etc. Until the late 20th century, with the concept of sustainable development gradually rooted in people's mind, they began to realize that the development and utilization of energy and mineral resources also have enormous eco-environmental effects in addition to their role in promoting rapid socio-economic development. Accordingly, the academic research on energy issues has gradually incorporated new keywords such as "ecological environment (eco-environment)", "low-carbon/recycling economy", "energy saving and consumption reduction", "carbon emission" and so on. So far, researches related to energy and mineral resource issues have largely been conducted from national or provincial perspectives, mainly including the spatial pattern and flow of energy and mineral resources, production and consumption structures and their influencing factors, etc. (Shen et al., 2012; Ma et al., 2010; Ma et al., 2014). Under the background of energy prices continuously fluctuating both at home and abroad and constructing ecological civilization, the consumption of traditional energies, like coal and oil, are faced with enormous supply-demand contradiction and huge eco-environmental pressure as well. Thus, the development and utilization of new energy resources, such as solar energy, biomass energy and so on, continuously enter the vision of researchers (Yang et al., 2008; Yan et al., 2010), and become the new impetus for achieving energy saving and emission reduction targets and developing recycling economy. Besides, some scholars also devote themselves to the traditional study of energy efficiency and effectiveness including the efficiency and economic benefits of energy development and utilization (Liu, 2010), among which the "resource curse" hypothesis is still one of the hot topics of empirical research (Zhang et al., 2010). In recent years, the eco-environmental effects brought about by the development and utilization of energy and mineral resources have also gained more and more attention (Li et al., 2013; Zhang, 2006). Furthermore, in view of the role of energy as a strategic resource which is of special significance to national development, energy security and strategy has always been one of the hot issues in the field of energy research. Related research perspectives can be divided to two categories. One is the perspective of time from which the load degree and sustainable development ability of regional energy and mineral resources are assessed by establishing the "pressure-bearing force" double-level index system (Zhao et al., 2010; Shen et al., 2010). The other is the perspective of space from which domestic and international energy cooperation strategies and frameworks for geopolitical security is studied (Gu et al., 2002; Yang et al., 2015; Hu et al., 2014). Under the background of globalization, more attention should be paid to the study of energy security and strategies as well as the development and utilization of new energy resources.

\subsubsection{Eco-environment base research}

Whether the eco-environment is good or bad is closely related to the quality of our life. With the development of economy, people are paying more and more attention to ecological environment. The construction of eco-environment is also an important aspect of building a harmonious society. In recent years, China's ecological environment has gradually taken on new modern characteristics. The pollution caused by industry and public consumption are 
coexisting; so far as water body is concerned, industrial and agricultural population are intensifying; the scope of ecological and environmental deterioration is expanding; point source pollution is extending to an area domain (Fu et al., 2000). The strategic policy of vigorously promoting the construction of ecological civilization provides great opportunities and enormous challenges as well for eco-environmental research.

Scholars commit themselves to eco-environment related research and achieve plentiful valuable results from different perspectives, among which ecosystem assessment and eco-environmental quality evaluation, as one of the hot research areas, provides scientific references for finding out the value and development potential of eco-environment in China. The most representative researches are ecosystem status and function evaluation, including the assessment of ecosystem production and service capability to human development, and the evaluation of ecological, economic, and social values of different elements (such as land, forests, grasslands) (Fu et al., 2001; Liang et al., 2011; Zeng et al., 2009; Xiao et al., 2014; Sun et al., 2012). The impacts of human factors (human activities) and natural factors (earthquakes, climate change, etc.) on ecosystem have also been concerned by many scholars (Ouyang et al., 2008; Li et al., 2013). Besides, based on the principle of "the one who benefits compensates", ecological compensation, as one of the important means of protecting ecosystem and environment, has gradually become another major direction of eco-environment related research. In order to enhance the service function and sustainable development capacity of ecosystem, current researches tend to be based on the value evaluation of ecological resources, and further explore the theoretical basis, standards, patterns, methods and effects of ecological compensation (Mao et al., 2002; Xiong et al., 2004; Qin et al., 2007). Eco-security and protection has also been a hot topic in recent years, and relevant research themes show a trend of shifting from the macro perspective of "national eco-security" to meso, micro and featured perspectives such as "urban eco-security", "basin eco-security", "agriculture eco-security", "land eco- security" and so on. Similarly, related researches are also conducted based on an overall assessment of ecosystem, and then further analysis is made on the security situation and strategic measures of specific regions, specific types or specific development stages of ecosystem, based on which scientific advices for ecological protection and construction can be proposed (Shi et al., 2015; Qin et al., 2014; Xie et al., 2014). As one of the criteria for evaluating the sustainable development ability of eco-environment, ecological carrying capacity also catches the attention of many scholars, especially the research on the ecological capacity of special and typical regions (Xiong et al., 2012; Liu et al., 2012; Dong et al., 2007). Major research methods are qualitative analysis, comprehensive evaluation, state-space method, ecological footprint, resource-demand difference method, estimation of net primary productivity of vegetation, model simulation and so on. Modern technologies, such as remote sensing and geographical information system (GIS), are increasingly applied to eco-environment related research, which can provide technical support for acquiring full-scale dynamic testing data.

\section{Future prospects}

In the age of ecological civilization, to correctly understand the relationship between man and nature is the key to coordinate the relationship so as to achieve the goal of sustainable 
development. Although we have made great progress in concept and theoretical methodology of man-land relationship research, in the face of growing global resources and environmental problems, more efforts still need to be made for further research. Especially under an unceasingly changing background, the two hot issues concerned by the science circle, i.e. global environmental change and sustainable development are both closely related to man-land relationship (Zheng, 2002). Meanwhile, it is actually more accurate to describe our national resources and environmental base as "vast territory with limited resources" rather than "vast territory with abundant resources" as before. Therefore, it is particularly important to re-understand the resource-environment base of man-land relationship research.

In coming researches of man-land relationship, developed and dynamic thinking should be introduced, which embodies three meanings. First, for the connotation of man-land relationship always changes with times, accordingly, we should also constantly deepen our understanding of the connotation of man-land relationship in a developing view. In modern times, the relationship between human and the earth in China has taken on some new features. So far as the elements of "land system" are concerned, along with the increasingly improvement of the three-dimensional traffic network, the local limitations of resources production and consumption have been weakened by the cross-regional flowing of resources. Additionally, rapid urbanization is also changing human dependence on different land use types. As for the elements of "human system", as the dominant factor in man-land relationship, population size and growth has always been the logic base of man-land relationship related research and resource and environmental carrying capacity evaluation. However, as living standards are rising continuously, people pay more and more attention to "the quality of life" instead of "the quantity of population". Meanwhile, the transformation from pursuing the speed of economic growth to starting economic restructuring also leads to changes in people's living demand structure. Therefore, when studying modern man-land relationship and its resource-environment base, we must profoundly understand the real connation of various elements in man-land relationship system in accordance with new characteristics of the time. Secondly, close attention should be paid continuously to the influences of new factors on man-land relationship research in geography. Informatization and globalization have altered people's perception about time and space and have become a challenge to traditional location theory of geography. However, this does not mean that regional disparity has disappeared. On the contrary, the disparities in regional development caused by the differences in the degree of informatization are worthy of more attention. In the information age, whether the spatio-temporal distortions caused by the new connotations of man-land relationship to the absolute location of resource environment will affect the interaction pattern between human and earth or not also needs further study. Thirdly, the profound study and quantitative simulation should be further strengthened. Man-land relationship issues have been raised since a very long time ago. Macro- and medium-scale qualitative and quantitative researches done only from the perspective of time sections are far from enough to deeply understand the connotation of man-land relationship and its evolution rules so as to coordinate man-land relationship in the direction of sustainable development. Comprehensive understanding of man-land relationship should be further deepened, especially the longitudinal cognition from multiple scales. Multi-scale man-land relationship evolution rules should be quantified, major controlling factors should be identified, and optimum man-land 
relationship mode can then be inversed in combination with future socio-economic development goals as well as resources and environmental carrying threshold and regulating measures for harmonious relationship between human and earth be refined.

Cross-disciplinary research and research on the comprehensive integration technical support system need to be strengthened, and emphasis also needs to be placed on the construction of research teams and the cultivation of new blood in the meantime. For the research of man-land relationship involves a wide range of fields, full attention should be paid to the interpenetration and mutual enlightenment among different research directions. When conducting the bibliometric analysis above, we found that the connection between related studies in this field is loose and the research structure is not compact, which may have to do with the vast subject system of man-land relationship research. Meanwhile, this also remind us of the importance of taking full advantage of the strength of different disciplines and research directions and laying emphasis on the interpenetration and mutual enlightenment among different discipline systems so as to promote the theoretical and practical development of man-land relationship and gradually expand the research team. Although the sub-disciplines of Geography, i.e. human geography, physical geography and geographic information system, have established their own exquisite sub-disciplinary systems, we should not blindly consider them as completely independent subjects when doing related research. Furthermore, we should speed up methodological innovation and the application of modern technologies. The technical methods of the comprehensive studies of man-land relationship and its resource-environment base are both in need of further development. Modern technological measures like GIS, remote sensing should be employed to collect and improve related data of man-land relationship study and long-term tracking are needed on the evolution parameters of man-land system in typical regions, so as to provide methodological and technical support for achieving instant cognition and coordination of man-land relationship.

\section{References}

Cai Y L, 1998. A paradigm of the research on man-earth relationship: Positive study of territorial system. Human Geography, 13(2): 7-13. (in Chinese)

Cai Y L, 2001. A study on land use/cover change: The need for a new integrated approach. Geographical Research, 20(6): 645-652. (in Chinese)

Chen B M, Liu X W, Yang H, 2003. Review of most recent progresses of study on land use and land cover change. Progress in Geography, 22(1): 22-29. (in Chinese)

Chen H L, 2000. A study on basic territorial differences in the man-land system in karst regions of South China. Geographical Research, 19(1): 73-79. (in Chinese)

Chen S, 2009. Energy consumption, $\mathrm{CO}_{2}$ emission and sustainable development in Chinese industry. Economic Research Journal, (4): 41-55. (in Chinese)

Chen Y F, Sun H, Liu Y S, 2010. Reconstruction models of hollowed villages in key agricultural regions of China. Acta Geographica Sinica, 65(6): 727-735. (in Chinese)

Ding S B, 2009. Some basic theoretical issues faced with plan of essential function region system. Scientia Geographica Sinica, 29(4): 587-592. (in Chinese)

Dong C S, Chen D L, Dong M H et al., 2007. Forecasting system for ecological carrying capacity of Wulingyuan Scenic spot based on ANN. Acta Ecologica Sinica, 27(11): 4766-4776. (in Chinese)

Duan C Q, Liu C M, Chen X N et al., 2010. Preliminary research on regional water resources carrying capacity conception and method. Acta Geographica Sinica, 65(1): 82-90. (in Chinese) 
Fan J, 2007. The scientific foundation of major function oriented zoning in China. Acta Geographica Sinica, 62(4): 339-350. (in Chinese)

Fan J, Wang C S, Tang Q et al., 2014. Comprehensive geographic analysis and discussion on strategies for post-earthquake recovery and reconstruction in Ludian, Yunnan Province. Progress in Geography, 33(8): 1011-1018. (in Chinese)

Fang C L, 2004. Recent progress of studies on man-land relationship and its prospects in China. Acta Geographica Sinica, 59(Suppl.): 21-32. (in Chinese)

Feng Y L, Han W X, Wang H J et al., 2003. Study on the sustainable development oriented optimal allocation to region water resources. System Engineering Theory \& Practice, (2): 133-138. (in Chinese)

$\mathrm{Fu}$ B J, Chen L D, Yu X B, 2000. The new trends and counter-measurements on eco-environmental issues in China. Environmental Science, 21(5): 104-106. (in Chinese)

Fu B J, Liu S L, Ma K M, 2001. The contents and methods of integrated ecosystem assessment (IEA). Acta Ecologica Sinica, 21(11): 1885-1892. (in Chinese)

Fu X F, Cao W D, Cao Y H et al., 2005. Change of land-use and environmental effect in peri-urbanization region: A case study of Xinjin county in Chengdu. China Population Resources and Environment, 15(3): 80-83. (in Chinese)

Gao X L, Chen T, Fan J, 2010. Population capacity in the Wenchuan earthquake reconstruction areas. Acta Geographica Sinica, 65(2): 164-176. (in Chinese)

Gao Y C, Liu C M, 1997. Limit analysis on the development and utilization of regional water resources. Journal of Hydraulic Engineering, 28(8): 73-79. (in Chinese)

Gao Z Q, Liu J Y, Zhuang D F, 1999. The research of Chinese land-use/land-cover present situations. Journal of Remote Sensing, 3(2): 134-138. (in Chinese)

Graymore M L M, Sipe N G, Rickson R E, 2010. Sustaining human carrying capacity: A tool for regional sustainability assessment. Ecological Economics, 69(3): 459-468.

Gu S Z, Geng H Q, Yao Y L, 2002. The compartmentalization of functional areas for national resource security and the orientation of the west China. Progress in Geography, 21(5): 410-419. (in Chinese)

Guo A Q, Ge J F, 2006. Evaluating intensive use of urban land in Hebei Province. Resources Science, 28(4): 65-70. (in Chinese)

Guo Y, Wang Z C, 2001. Man-land relationship in historical evolution. Journal of Chongqing Normal University (Natural Science Edition), 18(1): 23-25. (in Chinese)

$\mathrm{Hu}$ T L, Yang Z F, 2004. Method for ecological benefit assessment of rural land consolidation. Transactions of the Chinese Society of Agricultural Engineering, 20(5): 275-280. (in Chinese)

$\mathrm{Hu}$ Z D, Ge Y J, Xu J W, 2014. Geopolitical energy security evaluation method and its application based on politics of scale. Geographical Research, 33(5): 853-862. (in Chinese)

Huang M H, Luo Y M, 2003. Land remediation and ecological restoration of mined land. Acta Pedologica Sinica, 40(2): 161-169. (in Chinese)

Hui Y H, Jiang X H, Huang Q, 2001. On system dynamic simulation model of water resources bearing capacity in duality mode. Geographical Research, 20(2): 191-198. (in Chinese)

Jia R X, Liu Y, 2003. China's regional sustainable development status quo and its classification. Geographical Research, 22(5): 609-617. (in Chinese)

Jia S F, He X W, Xia J, 2004. Problem and countermeasures of water resources security of China. Bulletin of Chinese Academy of Sciences, 19(5): 347-351. (in Chinese)

Jia S F, Zhang J Y, Zhang S F, 2002. Regional water resources stress and water resources security appraisement indicators. Progress in Geography, 21(6): 538-545. (in Chinese)

Jiang W L, 2001. Study on water resource safety strategy for China in the 21th century. Advances in Water Science, 12(1): 66-71. (in Chinese)

Jiang Z M, 2008. Reflections on energy issues in China. Journal of Shanghai Jiaotong University, 42(3): 345-359. (in Chinese)

Kang S Z, Cai H J, Feng S Y, 2004. Technique innovation and research fields of modern agricultural and ecological water-saving in the future. Transactions of the Chinese Society of Agricultural Engineering, 20(1): 1-6. (in Chinese) 
Lai H L, Wang D X, Wu D F, 2007. Comprehensive assessment indicator system for water resources and its development and use. Advances in Water Science, 17(1): 95-101. (in Chinese)

Lei X P, Qiu G H, 2016. Empirical study about the carrying capacity evaluation of regional resources and environment based on entropy-weight TPOSIS model. Acta Scientiae Circumstantiae, 36(1): 314-323. (in Chinese)

Leng S Y, Li X B, 1999. New progresses of international study on land quality indicators. Acta Geographica Sinica, 54(2): 83-91. (in Chinese)

Li G P, Guo J, 2013. The study of the ecological environment restoration in energy-rich region. China Population, Resources and Environment, 23(7): 42-48. (in Chinese)

Li J, Li X J, 2008. The microscopic analysis on village-hollowing in medium income and hilly land region of Henan province. China Population, Resources and Environment, 18(1): 170-175. (in Chinese)

Li J Y, Li L J, 2012. Water resources supporting capacity to regional socio-economic development of China. Acta Geographica Sinica, 67(3): 410-419. (in Chinese)

Li L J, Zheng H X, 2000. Environmental and ecological water consumption of river systems in Haihe-Luanhe basins. Acta Geographica Sinica, 55(4): 495-500. (in Chinese)

Li R, Yang Q K, Wen Z M et al., 2002. Review of research on regional land use change and its environmental impacts. Bulletin of Soil and Water Conservation, 22(2): 65-70. (in Chinese)

Li Y F, Luo Y C, Liu G et al., 2013. Effects of land use change on ecosystem services: A case study in Miyun reservoir watershed. Acta Ecologica Sinica, 33(3): 726-736. (in Chinese)

Liang L T, Qu F T, Feng S Y, 2011. Rural ecosystem service value in China: Evaluation and temporal and spatial characteristics. China Population, Resources and Environment, 21(7): 133-139. (in Chinese)

Liu D, Feng Z M, Yang Y Z, 2012. Ecological balance between supply and demand in China using ecological footprint method. Journal of Natural Resources, 27(4): 614-624. (in Chinese)

Liu H, Geng L H, Chen X Y, 2003. Indicators for evaluating sustainable utilization of regional water resources. Advances in Water Science, 14(3): 265-270. (in Chinese)

Liu J J, Dong S C, Li Z H, 2011. Comprehensive evaluation of China's water resources carrying capacity. Journal of Natural Resources, 26(2): 258-269. (in Chinese)

Liu J Y, Zhang Z X, Zhuang D F, 2003. A study on the spatial-temporal dynamic changes of land-use and driving forces analyses of China in the 1990s. Geographical Research, 22(1): 1-12. (in Chinese)

Liu L T, Shen L, 2010. Spatial-temporal evolution pattern and influential factors of regional total factor energy efficiency in China. Journal of Natural Resources, 25(12): 2142-2153. (in Chinese)

Liu S H, Deng Y, Hu Z, 2010. Research on classification methods and spatial patterns of the regional types of China's floating population. Acta Geographica Sinica, 65(10): 1187-1197. (in Chinese)

Liu Y, Liu Y Z, Xu P, 2004. Evaluation on ecological security of regional land resources: A case study of Jiaxing city, Zhejiang province. Resources Science, 26(3): 69-75. (in Chinese)

Liu Y, Yang Y, 2014. Serious problems faced by China's population, resources, and environment and new thinking on the countermeasures. Bulletin of Chinese Academy of Sciences, 29(2): 248-257. (in Chinese)

Liu Y S, Chen B M, 2002. The study framework of land use/cover change based on sustainable development in China. Geographical Research, 21(3): 324-330. (in Chinese)

Liu Y S, Feng D X, 2001. Sustainable potential and models of land use in the Three Gorges Reservoir area. Geographical Research, 20(2): 139-145. (in Chinese)

Liu Z G, Wang C, Li E L et al., 2014. Research progress of economic geography in China. Acta Geographica Sinica, 9(10): 1149-1458. (in Chinese)

Long H L, 2003. Land rehabilitation and regional land use transition. Progress in Geography, 22(2): 133-140. (in Chinese)

Long T R, Jiang W C, He Q, 2004. Water resources carrying capacity: New perspectives based on eco-economic analysis and sustainable development. Journal of Hydraulic Engineering, (1): 38-45. (in Chinese)

Lu D D, 2002. Theoretical studies of man-land system as the core of geographical science. Geographical Research, 21(2): 135-145. (in Chinese)

Lu D D, Fan J, 2009. 2050: Regional Development of China. Beijing: Science Press. (in Chinese) 
Lu D D, Guo L X, 1998. Man earth areal system: The core of geographical study: On the geographical thoughts and academic contributions of academician Wu Chuanjun. Acta Geographica Sinica, 53(2): 97-105. (in Chinese)

Luo M, Wang J, 2001. A study on regional differences of land consolidation in China and suggestions. Progress in Geography, 20(2): 97-103. (in Chinese)

Luo M, Zhang H Y, 2002. Land consolidation and its ecological and environment impacts. Resources Science, 24(2): 60-63. (in Chinese)

Lv L C, Huang R, 2013. The cognitive map of relationship between human-earth. Economic Geography, 33(8): 5-9. (in Chinese)

Ma B B, Lu C X, Zhang L et al., 2010. The temporal and spatial patterns and potential evaluation of China's energy resources development. Journal of Geographical Sciences, 20(3): 347-356. (in Chinese)

Ma L, Jin F J, 2014. Analysis of the spatial pattern and main driving factors of China's coal self-sufficiency rate. Economic Geography, 34(7): 90-96. (in Chinese)

Mao H Y, 1995. On Man-land System and Regional Sustainable Development. Beijing: China Science and Technology Press. (in Chinese)

Mao X Q, Zhong Y, Zhang S, 2002. Conception, theory and mechanism of eco-compensation. China Population, Resources and Environment, 12(4): 40-43. (in Chinese)

Ni S X, Liu Y S, 1999. Study on optimal allocation of land resource and its sustainable use. Rural Eco-environment, 15(2): 8-12, 21. (in Chinese)

Ouyang Z Y, Xu W H, Wang X Z et al., 2008. Impact assessment of Wenchuan earthquake on ecosystem. Acta Ecologica Sinica, 28(12): 5801-5809. (in Chinese)

Ouyang Z Y, Zhao T Q, Wang X K et al., 2004. Ecosystem services analyses and valuation of China terrestrial surface water system. Acta Ecologica Sinica, 24(10): 2091-2099. (in Chinese)

Pei Y S, Li Y L, Yu F L, 2003. Discussion on water right allocation of replaced water from Yellow River. Resources Science, 25(2): 32-37. (in Chinese)

Peng B Z, An X D, Chen F et al., 2001. A study on sustainable land use in the Yangtze River Delta. Journal of Natural Resources, 16(4): 305-312. (in Chinese)

Qi W, Liu S H, Zhao M F, 2015. Study on the stability of Hu Line and different spatial patterns of population growth on its both sides. Acta Geographica Sinica, 70(4): 551-566. (in Chinese)

Qiao J J, 2015. Quantitative research of regional man-land relationship. Human Geography, (1): 81-85. (in Chinese)

Qin C, Wang H Q, Tian Y N et al., 2011. Study on evaluation indexes of resources and environmental carrying capability. China Population, Resources and Environment, 21(Suppl.2): 335-338. (in Chinese)

Qin X N, Lu X L, Wu C Y, 2014. The knowledge mapping of domestic ecological security research: Bibliometric analysis based on citespace. Acta Ecologica Sinica, 34(13): 3693-3703. (in Chinese)

Qin Y H, Kang M Y, 2007. A review of ecological compensation and its improvement measures. Journal of Natural Resources, 22(4): 557-567. (in Chinese)

Shen L, Liu L T, Gao T M et al., 2012. The quantity, flow and functional zoning of energy resources in China. Resources Science, 34(9): 1611-1621. (in Chinese)

Shen L, Liu L T, Zhang Y, 2010. The theoretical analysis framework and empirical study on the complexity of regional energy security. China Energy, 32(11): 30-36. (in Chinese)

Shi Y L, 2006. Resource Science. Beijing: Higher Education Press. (in Chinese)

Shi Y L, Yu G R, Wang H et al., 2015. Assessment of China's ecological environment and strategic thinking. Resources Science, 37(7): 1305-1313. (in Chinese)

Sun D Q, Zhang J X, Zhu C G et al., 2012. An assessment of China's ecological environment quality change and its spatial variation. Acta Geographica Sinica, 67(12): 1599-1610. (in Chinese)

Sun F H, 2012. Speculation of human-earth harmony theory based on yi studies and geomancy. Acta Geographica Sinica, 67(2): 266-282. (in Chinese)

Sun W, Hou Y, Zhang B, 2000. An approach to the fluctuation relation among land productivity, population pressure and weakness in ecotone. Acta Ecologica Sinica, 20 (3): 369-373. (in Chinese) 
Tan X, Shi L, Wang X J et al., 2016. Regional water efficiency evaluation and deconstruction analysis of the New Silk Road Economic Belt. Journal of Aid Land Resources and Environment, 30(1): 1-6. (in Chinese)

Wang A M, Liu J L, 2001. Progress in the study of man-land relationship in China. Tropical Geography, 21(4): 364-368. (in Chinese)

Wang J F, 1995. Man-land Relationship Evolution and Adjustment: Research on Global Change, Natural Disasters and Human Activities in China's Typical Areas. Beijing: Science Press. (in Chinese)

Wang L M, 1997. A theoretical and methodological study on the PRED-oriented modeling of man-land relationship system. Geographical Research, 16(2): 38-44. (in Chinese)

Wang L M, Zhang S H, Zhang D Q, 2007. Modeling man-land tensity of China based on $1 \mathrm{~km}$ grid data. Geographical Research, 26(3): 425-432. (in Chinese)

Wang M, Qu F T, 2004. Indicator system for land use intensity assessment of industrial enterprises in Kunshan development zone. China Land Science, 18(6): 22-27. (in Chinese)

Wang S H, Mao H Y, 2001. Design and evaluation on the indicator system of land comprehensive carrying capacity. Journal of Natural Resources, 16(3): 248-254. (in Chinese)

Wang S Y, Zhang Z X, Zhou Q B, 2002. Study on spatial-temporal features of land use/land cover change based on technologies of RS and GIS. Journal of Remote Sensing, 6(3): 223-228. (in Chinese)

Wang Y H, Liu Y S, Zhou Y H, 2004. Analysis of human driving forces underlying land use conversion in coastal developed regions: A case study of Wenzhou city. Progress in Geography, 23(2): 43-50. (in Chinese)

Wang Z, 1995. On the modern meaning of the relationship between the man and the earth. Human Geography, 10 (2): 1-5. (in Chinese)

Wang Z B, Zhang Q, Zhang X R et al., 2013. Urban growth boundary delimitation of Hefei City based on the resources and environment carrying capability. Geographical Research, 32(12): 2302-2311. (in Chinese)

Wen Y M, Ke X K, Wang F, 1999. Study on assessment system and assessment method of sustainable development of human-earth system. Advance in Earth Sciences, 14 (1): 51-55. (in Chinese)

Wu C J, 1991. On the research core of geography: Man-land relationship areal system. Economic Geography, 11(3): 1-6. (in Chinese)

Wu D, Wang S D, Ma C, 2016. Modeling of urban water resources optimal allocation. Journal of Arid Land Resources and Environment, 30(2): 31-37. (in Chinese)

Xia J, Thomas Tanner, Ren G Y et al., 2008. Potential impacts of climate change on water resources in China: Screening for adaptation and management. Advance of Climate Change Research, 4(4): 215-219. (in Chinese)

Xia J, Zhai J L, Zhan C S, 2011. Some reflections on the research and development of water resources in China. Advances in Earth Science, 26(9): 905-915. (in Chinese)

Xia J, Zhu Y Z, 2002. The measurement of water resources security: A study and challenge on water resources carrying capacity. Journal of Natural Resources, 17(3): 262-269. (in Chinese)

Xia J, Zuo Q T, 2013. China's decade summary and prospect of water resources academic exchange. Journal of Natural Resources, 28(9): 1488-1497. (in Chinese)

Xiao Q, Xiao Y, Ouyang Z Y et al., 2014. Value assessment of the function of the forest ecosystem services in Chongqing. Acta Ecologica Sinica, 34(1): 216-223. (in Chinese)

Xie X F, Wu T, Xiao C et al., 2014. Ecological security assessment of the Dongyang River watershed using PSR modeling. Resources Science, 36(8): 1702-1711. (in Chinese)

Xiong J X, Chen D L, Xie X M, 2012. Comprehensive evaluation on ecological carrying capacity based on state-space techniques in Dongting Lake region. Economic Geography, 32(11): 138-142. (in Chinese)

Xiong Y, Wang K L, Lan W L et al., 2004. Evaluation of the lake recovery area eco-compensation in Dongting lake wetland. Acta Geographica Sinica, 59(5): 772-780. (in Chinese)

Xu Y, Sun X Y, Tang Q, 2015. Human activity intensity of land surface: Concept, method and application in China. Acta Geographica Sinica, 70(7): 1068-1079. (in Chinese)

Yan D H, He Y, Deng W et al., 2001. Ecological water demand by river system in East Liaohe River Basin. Journal of Soil and Water Conservation, 15(1): 46-49. (in Chinese)

Yan Q, Chen Y C, Wang A J et al., 2010. Development obstacles of new energies in China and countermeasures: A 
review on global current situation. Acta Geoscientica Sinica, 31(5): 759-767. (in Chinese)

Yang Y, Liu Y, Jin F J, 2015. Study on energy cooperation between China and the Central Asia and Russia under the view of energy geopolitics. Geographical Research, 34(2): 213-224. (in Chinese)

Yang Y, Yu H, 2008. The consumption structure of rural energy and utilization of new energy: Based on the second agricultural census data in Yancheng city. Chinese Development and Observation, (9): 37-40. (in Chinese)

Ye D F, 2001. The interactive mechanism of man-earth areal system and the sustainable development. Geographical Research, 20(3): 307-314. (in Chinese)

Yue X Y, Song L Y, 2008. Research review and prospect of land carrying capacity. Research of Soil Water Conservation, 15(1): 254-257. (in Chinese)

Zeng X G, Wang K, Cheng L et al., 2009. Non-use value evaluation of ecological resources in Sanjiangyuan region. China Environmental Science, 29(6): 589-593. (in Chinese)

Zhang H Y, Zhao X Y, Cai Y L, 1999. The driving mechanism of human forces to the land-use change in the karst mountain area: The case study of Guizhou province. Geographical Research, 18(2): 136-142. (in Chinese)

Zhang L, 1999. Resources and environment foundation and man-land relationship in modern China. China Population, Resources and Environment, 9(4): 32-37. (in Chinese)

Zhang L, 2006. Evolution of energy-ecosystem in west China. Journal of Natural Resources, 21(2): 188-195. (in Chinese)

Zhang L, 2008. The resource-environmental base: A start point for China's man-land relationship. Journal of Natural Resources, 23(2): 177-184. (in Chinese)

Zhang L, Liu H, 2002. An issue on the national security of natural resources and environment for China. China Population, Resources and Environment, 12(1): 41-46. (in Chinese)

Zhang L, Liu Y, 2004. An analysis on man-land relationship of eastern China. Acta Geographica Sinica, 59(2): 311-319. (in Chinese)

Zhang M, 2000. A study on the landscape pattern and differentiation of fragile environment in Yulin Prefecture. Geographical Research, 19(1): 30-36. (in Chinese)

Zhang W Z, Yu J H, Wang D et al., 2014. Study on Sustainable Development of Resource-based Cities in China. Beijing: Science Press. (in Chinese)

Zhang X, Niu S W, Ding Y X et al., 2010. Empirical analysis of the relationship between energy resource and economic growth in provinces of China: Based on "resource curse" hypothesis. Journal of Natural Resources, 25(12): 2040-2051. (in Chinese)

Zhang Z F, Chen B M, 2003. Primary analysis on land consolidation benefits. Transactions of the Chinese Society of Agricultural Engineering, 19(2): 210-213. (in Chinese)

Zhao J B, Mei X R, Xue J H et al., 1996. The effect of straw mulch on crop water use efficiency in dryland. Scientia Agricultura Sinica, 29(2): 59-66. (in Chinese)

Zhao M H, Han R Q, 2004. Comment on the domestic and foreign status quo of man-land relationship and man-land system. Areal Research and Development, 23(5): 6-10. (in Chinese)

Zhao Z Y, Song D L, 2010. Development sustainability analysis of Chinese fossil energy on ecological foot print model (1990-2006). Scientia Geographica Sinica, 30(1): 75-79. (in Chinese)

Zheng D, 2002. Prospects of studies on man-land relationship in the 21st century. Geographical Research, 21(1): 9-13. (in Chinese)

Zhou K, Fan J, 2015. Characteristics and influence factors of resources and environment carrying capacity in underdeveloped areas of China. Geographical Research, 34(1): 39-52. (in Chinese)

Zhou X F, 2015. The model of human-earth areal system based on Yin-yang of I Ching. Geographical Research, 34(2): 225-233. (in Chinese)

Zhu Y Z, Xia J, Tan G, 2003. Measurement and evaluation of water resources carrying capacity of northwest of China. Resources Science, 25(4): 43-48. (in Chinese)

Zong Y G, Wang R, Wang C G et al., 2007. Ecological suitability assessment on land use based on potential-constrain approach: The case of urbanized areas in Dalian city, China. Geographical Research, 26(6): 1117-1126, 1305. (in Chinese) 